\title{
Dance, Resilience and Social Transformation in the Global South
}

\section{Patty Abozaglo}

\section{Abstract}

This article is based on a presentation at the Colloquium: Being Human Today held in Stellenbosch, South Africa in December 2015. This reflection is inspired by the courage of many women and men, who form part of community- based organisations and local NGOs. These people living in constant threat, and danger and have been attacked by armed groups or security forces, in contexts of violent conflict in Peru and Colombia and many other parts of Global South. For these communities, these threats, attacks and other forms of violence are part of their daily lives. However, they continue to work at building peace and respect for their human rights despite the risks these efforts may bring to their own lives and their families.

The work of the Peace and Wellness Project is presented in the article, a dance and body movement approach to dealing with trauma in communities affected by violent conflict. In developing the project, I drew on and combined the methodologies of Capacitar International Multicultural Awareness and Trauma Healing Programme and Laban Dance and Body Movement of the Laban GuildUK.

\section{Keywords}

Trauma, dance, resilience, social transformation, global south, workshops, body movement

The project has consisted of over 20 workshops reaching 200 people living in remote rural areas affected by violent conflict. In Colombia, participants were indigenous people of the Nasa community (Cauca Region, West Colombia), women internally displaced and affected by gender-based violence (Cartagena, Northern Colombia); and community development workers (based in Caquetá Department, Southern Colombia). All of them were living and working in highly conflictive environments caused by politically motivated violence and mining extractive activities. In Peru, sessions were attended by women and men members of rural communities affected by mining activities. These participants included social leaders, health promoters, teachers and activists as well as small farmers from Northern Peru. Finally, women members of a Latin American Union network also participated. Their members are all women affected by the behaviour of the mining extractive industry in Colombia, Honduras, Argentina, Mexico 
Paraguay, and Ecuador among others. This group of participants had directly experienced or witnessed threats, intimidation or actual evictions from their land by mining companies.

In Ireland, I have facilitated over 20 two hour workshops sponsored by the Kildare Arts Service and Public Libraries, in their efforts to support members of the community of Kildare county affected by the financial recession since 2008. The Kildare Arts Service is a well-recognised government body with a vision and commitment to develop creative ways to engage arts in community life, including those most vulnerable, enabling them to enjoy and benefit from access to a wide range of cultural activities. Workshops using Capacitar and Laban Dance were attended by approximately 150 people women and men searching for jobs, grandmothers who were minding their grandchildren as their own children were looking for employment, and active aging groups such as McAuley Place and the University of the Third age- U3A Maynooth. In other cases, participants were preparing for job interviews and needed to work on their own personal development and confidence building. Finally, active aging groups have actively participated in these workshops.

This initial exploration focused on approaches that strengthened creativity and addressed trauma at individual and collective levels. The ultimate goal of this project is to look at how creative and innovative methodologies using dance and body movement contribute to sustaining social processes of peacebuilding with attention given to healing trauma, and restoring social fabric in the long-term.

\section{Colombia and Peru: Overview of the context}

The Capacitar and Laban Dance Peace and Wellness Project took as a starting point the experience of communities that for decades were affected by traumatic events caused by protracted conflict in Colombia having an impact on the lives of individuals, and entire communities shaken by trans-generational trauma including Post Traumatic Stress Disorder (PTSD). In Colombia, where a peace process has been held since October 2012, previous peace processes failed because of lack of the participation of civil society in these processes (Duran, 2004). Violent conflict between guerrilla, paramilitary and state forces has caused death of thousands and eviction of over 5 million people who are now internally displaced. There is a felt need to make civil society be part of negotiations and sustain peace processes. Despite scepticism, the hope is that the peace process will overcome numerous challenges to make the peace agreement last. Several questions remain to be answered. These questions include: How to involve civil society, especially those most affected, in peacebuilding processes? How to make peace processes meaningful, engaging and effective for those at the grassroots? J.P. Lederach (2005) echoes the views of many civil society organisations which are searching for new ventures to build inclusive, lasting positive peace though the use of the imagination and creativity as those featured below.

\section{Colombia}

The project included three organisations. Vicaria Sur (VISUR), a team of 16 people who are part of a local NGO based in Southern Colombia. For the past 30 years, VISUR's rural development and 
human rights advocacy work is right in the heart of communities affected by the presence of guerrilla, paramilitary, state forces and, in the recent past, by mining companies as well. Having been trained in the programme, Youth Officer Juanita Gonzales leads youth groups in the practice of Capacitar and Laban Dance. Other groups who are engaging in the project are: Fundación Santa Rita- FUNSAREP- local NGO based in one of the poorest parts of Cartagena city working in education projects for the AfroColombian population who live in this area. They are currently implementing a psychosocial programme with the participation of over 30 women affected by gender-based violence and internal displacement due to the armed conflict. Another group participating in the project is Corporación de Apovo a

Comunidades Populares-CODACOP _ Colombian NGO working with women indigenous of the Nasa indigenous group affected by armed conflict, violence and mining activities in the Cauca Region, West Colombia.

\section{Peru}

In Peru, the economy is showing prosperity and a raise of growth indicators. However, wealth is not reaching all sectors in society. One example of this situation is the Northern Department of Cajamarca, where rural communities have experienced social and political tension relating to the gold mining industry. The practices of this industry had led to fear, grief, deprivation, violence and death in areas where gold was found. These communities have suffered the trauma of seeing their relatives, friends, and fellow citizens being threatened, harassed or killed, when trying to protect community land which is close to lakes that hold the gold mines. The Capacitar and Laban Dance Peace and Wellness project partnered with Plataforma Institucional (PIC), a coalition of 40 community-based social groups who campaign against the mega mining project CONGA and the mega hydroelectric project in Celendín, Cajamarca. PIC leaders are members of the community and include teachers, health promoters, and nurses among others. One of their activists is an Irish writer and teacher, Lynda Sullivan, who is based there and has documented the struggles of the community after the mining company evicted small farmers from their land to extract the gold in river basins (Sullivan, 2014). Since they took the Peace and Wellness Programme I delivered in 2013 and 2014, a group of community members led by Lynda Sullivan and PE teacher Livaque meet on a weekly basis replicating the practices with members of the community.

\section{Commonalities}

Despite differences in the context of these two settings in Colombia and Peru, there are common issues among them. Both are currently experiencing the impact of conflict due to mining extractive industry and there is potential for great learning and exchange that would enhance their capacity, solidarity actions and promote exchange and learning. Eviction processes are ongoing and members of the community have been prosecuted for speaking out in defence of their rights. Fear and mistrust are fracturing and weakening the social fabric and the capacity of the community to protect its own rights. Therefore, the experience of the Peace and Wellness Project aims to enhance the advocacy capacities of these communities to stand up for themselves and claim their rights and buildpeace. 


\section{Reflecting on Social Transformation, Violent Conflict and Trauma}

Social transformation (Hope \& Timmel, 2005) understood as a process about transforming/ changing ourselves, our communities and our society into sources of justice and equality is being challenged by a number of factors including poverty, inequality and more recently climate change (Dreissen, 2013), migration (Lindley, 2014) and extractive industry (Davis \& Franks, 2014). This creates tensions and conflict in communities about the use of the land and natural resources. These conflicts manifest in violence, death, destruction and serious human rights abuses that destroy, and threaten the lives and livelihoods of individuals and entire communities who for generations have depended on land tenure.

In Colombia and Peru, armed, violent conflict is having negative and destructive consequences for individuals and communities, imposing an enormous burden of psychological and social suffering on affected populations. Unhealed traumas may contribute to ongoing cycles of violence jeopardising development and/or peacebuilding effort (Wessells, 2008).

After more than two decades of experience working in human rights, international development and peacebuilding, I found out that communities in the south, especially in Colombia and Peru, were eager and open to look for other alternatives and creative methodologies. They sought more holistic interventions that would support social transformation processes by: 1) addressing the impact of trauma and Post Traumatic Stress Disorder (PTSD) at individual level and collective level, 2) restoring the social fabric of their communities and organisations 3) creating space for wellness and wellbeing using self- care methodologies, 4) strengthening community based organisations and its members affected by violent conflict and social tensions in the defence for their human rights and peacebuilding efforts. Other contributions to social transformation processes sought by these communities are; 5) supporting human rights defenders, and social activists' physical and mental health, 6) improving the ability to deal with conflict, fulfil human rights, enhance resilience, and finally 7) reverting patterns of violence through participation in a meaningful manner in lasting peace dynamics in the long-term.

Maxima Chaupe, Peruvian farmer and community leader has been under threat and attacks and prosecuted because of expressing her disagreement with the Mining Conga Project which will take her away from her land. Mining Company Yanacocha has offered 1.5 million sterling pounds for her to move out. She said that no money will pay for her livelihoods and her land where her family lives. Maxima attended a Capacitar and Laban sessions feeling very stressed out because of all the threats and intimidation received. After the session she said, "the session helped me to feel more relaxed and to gain strength to keep going."

More information on Maxima's situation and mining in Peru to be found in: https://congaconflict.wordpress.com/tag/maxima-chaupe/ 


\section{Trauma and its impact individually and collectively}

For the purpose of this article, trauma is defined as "the destruction of the individual and/or collective structures" via a traumatic situation, which in turn is defined as "an event or several events of extreme violence that occur within a social context" (Clancy \& Hamber, 2008: 3). Trauma is also understood as a collective phenomenon that erodes confidence and trust, and breaks social fabric (Ascensio, 2015). Trauma, is a notion that is simultaneously a socio political event, a psycho-physiological process, a physical and emotional experience, and a narrative (Kirmayer, 1996). Trauma is having an enormous impact in bodies and minds as well as in social, collective processes and dynamics ${ }^{\mathrm{i}}$, and if not addressed can jeopardise peace efforts and maintain patterns of violence in society.

All participants in this project have been affected by primary trauma and in the cases of carers and NGO or development workers, secondary (vicarious) trauma. It was perceived that Post-Traumatic Stress Disorder (PTSD) at individual and collective levels including secondary (vicarious) trauma have not been yet fully addressed by development/peacebuilding efforts. I have found in my long practice in development work that trauma is recognised by humanitarian or emergency interventions but not considered an issue to be addressed and included in medium/long term development projects. Counselling and psychotherapy were the most common approaches selected in short term interventions and as mentioned before these presented challenges and were not very effective. Trauma, being a physical and emotional experience (Levine, 1997) requires attention so that individuals and communities could deliver development projects with an impact at personal and social or collective levels. Thus, the question was how members of entire communities could overcome PSTD symptoms without having any treatment or without paying attention to the symptoms (Pease, 2015). How societies can heal if attention is not paid to such an important issue when it is known that unhealed traumas at societal level can put in danger entire peace processes.

Participants express their interest in addressing these issues and are looking for new approaches such as dance and body movement provided in the Peace and Wellness project, in order to support communities living in the midst of violent conflict or political tensions. These communities call their efforts to survive resistance, to keep going and to keep up the "struggle" as mentioned by Celendín activists in Peru.

The approaches selected (Capacitar and Laban Dance) took into consideration studies carried out by INCORE- University of Ulster on Trauma, Development and peacebuilding that suggest that cognitive therapies are not as effective when applied in non-Western countries have been taken on board. These studies indicate that biomedical trauma models applied after humanitarian disasters have been severely criticised as an approach that ignores socio-political context. It reduces complex human responses to clinical phenomena; it tends to be individual in focus and neglects the wider social impact of conflict on communities; it ignores cultural expressions of suffering, community strengths and ways of coping, and people's activity priorities are not always accepted as they are not culturally grounded, are expensive and long-term processes focused on the individual rather than in communities (Sonpar, 2008). 
One example that illustrates this situation is Rwanda after the genocide, when development agencies invested millions of euros in counselling projects which faced serious challenges and didn't achieve the impact expected. Challenges presented included the increase of tensions and divisions in the community.

\section{Post Traumatic Stress Disorder- PSTD symptoms}

Participants of this experience identified the following symptoms at individual level and collective level:

At individual level $\quad$ At Collective level

$\begin{array}{ll}\text {-Depression, fatalism, hopelessness, grief } & \text {-Break up of community structures } \\ \text {-Anxiety } & \text {-Weakening/destruction of social fabric } \\ \text {-Overwhelming, fear } & \text {-Isolation/alienation } \\ \text {-Anger, paralysis } & \text {-Mistrust/FEAR } \\ \text {-Indecision } & \text {-Intolerance } \\ \text {-Sleeplessness } & \text {-More conflict and Violence } \\ \text {-Emotional Pain } & \\ \text {-Loss interest in life } & \\ \text {-Physical ailments, etc. } & \end{array}$

\section{Resistance or Resilience: Creating systems for healing communities}

The PWIAS roundtable of the Social Transformation Through Arts (STA) initiative offers a useful definition of resilience as a "system's capacity to generate a higher level of organization following a disruption, rather than simply a return to the steady state; and that the conditions that give rise to resilience can be understood as features of communities This last idea focuses attention on questions of collective responsibility, public policy, and the equitable distribution of resilience- generating resources, in contrast to focusing on individuals' characters or qualities"( LeBaron \& Cohen, 2013: 2).

Lederach and Lederach (2010: 11-12) provide a different point of view that resiliency is not a linear process or a system but an intuitive process. It is a capacity to develop spaces of human interaction, to stay in touch, rather than a process that takes place before, during and after spikes of violence or signing of peace agreements being this adhered or broken. In his experience, social healing occurs when communities, in the midst of open violence find a way forward searching for place, safety and voice.

Lederach and Lederach's concept of resiliency is associated with a metaphor. It refers to the quality of retaining the capacity to find a way back to expressing the defining quality of being and the essence of purpose. At the core of resiliency, the following capacities are mentioned: 
- Adaptability, resourcefulness and a capacity to face and creatively negotiate risky situations.

- Capacity to forge solidarity

- Capacity to sustain hope and purpose

- Capacity to adapt and negotiate creatively with the challengespresented.

- Capacity to respond as a mechanism by which communities hard hit by violence find an innovative way to survive

- In sum, the local collective becomes proactively engaged in purposeful ways that help them recover a sense of place, at-homeness and a voice (Lederach \& Lederach, 2010: 68-69).

Lederach's views were confirmed when Peace and Wellness participants were asked about the concept of resilience. Although these participants preferred to talk about Resistance rather than resilience, they understand that the word resistance gives them a political stand, which is based in their deep commitment for full compliance to human rights and non-violent peace.

Participants felt they were still discovering ways to gain strength to keep going. They felt they were at an initial state after the shock and trauma of violent events and not having the time to process what is going on. Their efforts were focused on protecting themselves (safety), responding to authorities and keeping their advocacy ongoing (expressing their voice), designing the best way to protect and defend their rights (trying to find a way forward) and trying to restore community dynamics (sense of homeness) affected by mistrust and fear.

These comments suggest an association with the notions of safety, voice (sound) and space that Lederach refers to. It denotes the community search for finding its way back and its purpose which are key qualities of resiliency. The advocacy efforts also talk about the component of solidarity, hope and purpose and about their capacity to negotiate creatively with the challenges presented, trying to find a new way to survive. Their efforts to restore the community dynamics speak about the search for their capacity to "stay in touch".

\section{Resilience vs. Resistance: Re-gaining strength and courage as the struggle continues}

Participants affirmed that individually, some daily activities helped them to keep going in their daily life such as time spent with their family, getting some time by themselves (not always possible for women responsible for the house work and minding their children). Singing and dancing were also mentioned. We have to remember that in Latin America singing and dancing are very much part of the culture.

The practices of Capacitar and Laban Dance allowed participants to create space in the community to get together, to spend time together despite the tensions, fears and uncertainty created by violence and conflict. As faces looked more relaxed and peaceful, people were able to engage gradually in a group dynamic that was playful and enjoyable. Dance and body movement were useful approaches to embody resilience capacities and qualities as described by Lederach. Laban Dance's key concepts focused on 
effort, actions, shape and space, include the notion of being in touch with self and others. Body movement and dance provided opportunities for human interaction in a step by step process respecting individual paces and rhythms but allowing participants in a respectful and non-judgemental way to engage in a non-verbal process of discovery to free themselves, heal themselves, being part of a group.

Through the workshops it was observed that methodologies used contribute to create mental, physical space to regain energies and keep the activism ongoing. In Cajamarca, activist Lynda Sullivan who participated in workshops carried out in 2013, and who is now continuing the practice in Celendín says, "the practices allow us to keep going. It is more resistance then resilience."

\section{Strengthening healthy dynamics in communities and organisations affected by violent conflict environments}

According to Vicaria Sur (VISUR) Team, they needed space for thinking, strategizing and find respite in order to find creative ways to keep working in such conflictive environment. Sessions created a space where people feel supported, held, energised and relaxed, creating conditions for better community cohesion, and trust. Sessions proved to be effective in creating a safe and fun environment, acknowledging the group energy whatever this would be (tired, sad, anxious, etc.).

Doing the practices in a circle confirmed what Lederach (2010) and several authors propose; that the notion of healing is circular and that reconciliation involves cyclical or circular movements. The Team is now using the techniques learned in their youth programme and in their team meetings.

It would be accurate to say that the Capacitar and Laban Dance offer great potential to generate peaceful and healthy community dynamics, as groups which have experienced it were able to release tension in their bodies and minds, creating a much relaxed and healthy community atmosphere which in time can help to gain strength at individual and collectivelevel.

It would be too soon to say how these approaches could develop various capacities to generate higher levels of organisation following disruption. Further research is needed to investigate in depth how Capacitar and Laban as Dance and Body Movement approaches can help/support communities and organisations to address the impact collective trauma at primary and secondary levels and influence systemic change.

\section{Capacitar, Laban Dance and Body Movement: How it all works}

These two approaches are aimed at bringing awareness of and addressing individual and collective trauma, and symptoms of post-traumatic stress disorder at primary and secondary (vicarious) levels, as well as creating space for creativity and wellness of community activists and population directly affected by violent conflict.

Capacitar, founded by Pat Cane, is an international network working in over 35 countries in the Americas, Africa, Europe, the Middle East and Asia. At a conceptual level, their Multicultural 
Awareness and Trauma Healing Programme, uses neuroscience concepts proposing that the body has the capacity to heal using non cognitive methods and affirming the role of communities as the space to do that. It comprises a number of energy based techniques, using the concept of channels of energy or meridians and the experience of various energy - based protocols. These include: breath work, simplified Tai Chi, acupressure points to alleviate stress symptoms, body movement sequences, as well as Emotional Freedom Technique (EFT) and more. Capacitar ("empower "in Spanish) proposes a hands-on popular education approach, based on Paulo Freire's thinking. It teaches simple wellness practices that lead to healing, wholeness and peace in the individual and in the world. Capacitar is especially committed to communities affected by violence, poverty and trauma, uniting people across borders in solidarity, understanding and reconciliation.

For the past three decades, the Capacitar International programme has offered tools to address PSTD, arriving at the conclusion that cognitive approaches are not always effective, as cultural diversity poses challenges to the use of psychotherapy for example. These approaches are not always available and are not always culturally grounded. They focus on the individual rather than the group or community, sometimes generating additional conflicts to the ones they already experience. Capacitar practices have proved to be effective in addressing individual trauma and some indication of systemic level change has been found (Rebmann \& Cane, 2011).

Capacitar International Programme in Action

Capacitar practices are guided practices where the tutor describes the movement and meaning of it. Participants follow. These practices engage body movement with mindfulness connecting body mind and spirit. It creates a peaceful energy in the room, a sense of togetherness in silence. No words are needed to acknowledge pain, sorrows and challenges; the practice in a circular unifies participants in a soft and mindful manner allowing participants to feel held, individually and as a collective.

Laban Dance and Body Movement, founded Rudolph Laban (Hungary, 1879- 1958), is considered a revolutionary method of movement notation that continues to be used today. His theories of choreography and movement are now foundations of the modern dance. It is one of the most widely used systems of human movement analysis today.

Laban figures in the evolution and development of modern dance in Central Europe. He started his career as a painter and architect, then a choreographer. He was a movement researcher. His aim was to research the principles of human movement. His ideas created innovation in dance, performance and study of non-verbal communication, ergonomics and education theory as well in the study of child development, the evaluation of personality and psychotherapy. Laban's work has been applied in dance creation, performance and teaching in both professional and community contexts; dance therapy and 
dance for special needs; psychology, anthropology and ethnology; acting and drama; dance and gymnastics in education; industry and management. He believed in dance as a tool for social change.

Sessions include individual and group explorations based on body movement fundamentals developed by Rudolph Laban such as: body shapes, body actions, use of space and effort. In Laban terms, effort is defined as the inner impulse to action and the colouring of the movement which gives it expressive/dynamic quality.

Laban Dance and Body movement is being used as a tool by dancers, actors, musicians, educators, athletes, physical and occupational therapists, psychotherapy, peace studies, anthropology, business consulting, leadership development, health \& wellness.

\section{Example of Laban Exercises: Follow the Leader and Mirroring}

In lines of 4 or 5 people, the first in the queue starts moving freely using the space around, the people behind imitates the leader. After a while, the leader moves to the back of the queue and the second person in the line takes the leader's role leading the movement. Every person in the line has the opportunity to be a leader and a follower.

Other exercises include individual and collective movement explorations mirroring and constructing movement phrases at individual level first which are combined later with others in the group forming group movement phrases. In pairs, participants are asked to decide who would lead and who would follow. After a few moments they change roles. This is free movement.

Comments/observations: This is a useful exercise to reflect on how people feel being a leader or a follower. It has also proved to be useful to reflect on human rights and governance issues namely, space for democratic expression or space for participation. It is an effective exercise to reflect on leadership, how people feel when they lead and/or when they follow. It has been observed that severely traumatised people have a lot of movement restrictions and they found very difficult to lead and follow.

It was observed that after a while the leader and follower movements merge and no effort is needed to lead or follow. All this proves the point about how kinesthetic empathy works and allows participants to align and syncronised movement creating a safe environment where people feel included, free and happy ( Doung, 2013).

\section{The Sessions}

Sessions start using Capacitar practices including deep breathing visualisation (body mapping or body literacy) followed by sequences of simplified Tai chi. Depending on the group and the time allocated for the session protocols such as Emotional Freedom Technique (EFT) or finger holds may follow.

Capacitar practices take place in a circle of body movement in silence. The tutor guides the session using the left and right sides of the body balancing sympathetic and parasympathetic systems. Circle practices 
help people to integrate, to feel included in a non-verbal manner.

This is followed by the second part of the session which consists of various Laban Dance and Body movement exercises where participants are able to explore their own movement and construct group movement sequences- dances. Starting with walking with awareness of themselves as individuals and their surroundings including the members of the group, this is a way to start moving in a gentle and mindful manner. This is similar to the exercise proposed by Margie Phyllis in the Choreography of Resolution (Alexander \& LeBaron, 2013). Gently and slowly the group becomes aware of the others around. A short directed piece can bring people together in movement. This is followed by space to create movement phrases, individually first, and then these are shared with others in duos or trios. Instructions to create these movement sequences take the Laban concepts on body actions, body shapes, and space and effort qualities. A particular theme can also be introduced when exploring movement.

Both Capacitar and Laban approaches use body movement and dance elements. Their combined use has had very positive results in addressing symptoms of PSTD at individual and collective levels in the short-term. What still needs to be explored in depth is how these methods can assist communities to address inter- generational, collective trauma and how their practice and generate better group functioning and therefore avoid a return to cultural patterns of violence at community level.

Starting with Capacitar practices followed by Laban Dance exercises has proved very effective and successful. Participants engage much better and benefit more as Capacitar practices help to gain awareness of where their minds and bodies are at the beginning of the session. Starting with Capacitar practices means doing deep breathing body mapping and Tai Chi, and, depending on the length of the session, also other techniques such as finger holds and emotional freedom tapping technique (EFT). This is followed by Laban Dance and Body movement. It has been observed that when using these two methodologies in that order, people engage better and enjoy more. Face expressions show that people are relaxed and open, participants engage and enjoy fully. In some cases, physical pain disappears creating a sense of relief and peace. The effect of relaxation, integration and enjoyment as a group was not as evident when Laban is used at the beginning of the session.

Capacitar practices are done in a circle and offer a form of non-verbal communication, providing time to BE together, in a different way, not talking about problems, allowing bodies and minds to restore energy as a group, giving and receiving.

\section{Dance and Body Movement: A contribution to Social Transformation and Resilience building}

a. Gaining self and Group Awareness through gentle body movement: A process of empowerment, discover; a personal and groupjourney

It was observed that those practices allowed creating space in the community, to spend time together despite the tensions, fears and uncertainty created by violence and conflict. As faces looked more relaxed and peaceful, people were able to engage gradually in a group dynamic that was playful and 
enjoyable. Dance and body movement were useful approaches to embody resilience capacities and qualities, as described by Lederach and Lederach. Laban Dance's key elements focus on space, and the notion of being in touch with self and others favouring human interaction in a step by step process respecting individual paces and rhythms but allowing participants in a respectful and non-judgemental way to engage in a non-verbal process of discovery to free themselves, heal themselves, being part of a group.

\section{Laban Dance with Women affected by Gender Based Violence in Cartagena, Colombia}

Participants started telling their stories of horror, trauma, loss, described physical and emotional pain. At the end of the two-day workshop they said they felt liberated and happy and that they" forgot for a moment" their stories of trauma.

Cartagena, Workshop with women affected by Gender based violence, September, 2013

Insights from Women participants in Cartagena:

- "Learned that the body is like an engine that needs maintenance"

- "All practice belped me to relax and overcome fear"

- "All Capacitar techniques were useful"

- "Overcame fear using easy techniques"

- "Found the dancer in me"

- "Discovered my strength"

- "Forgot for a moment what happened to me"

- "Acknowledged the importance of leadership, my interests and needs"

b. Addressing Trauma at individual and community Level: creating the basis for healthier and peaceful societies

Capacitar and Laban approaches have been useful to address trauma - PSTD symptoms. People arrived with physical tensions, aches as well as emotional pain. At the end they feel more balanced, open, relaxed and energised. The combined approaches allowed focusing on the self-generate healthy and fun interactions with others. The assumption is that if people feel better they can function better and can engage in relationships in a much healthier manner. More investigation will be needed to see how these approaches can affect group dynamics and influence positive systemic change

c. Strengthening group integration, creativity and fun

Lynda Sullivan, Irish activist who was trained in 2013 and 2014, and is replicating the sessions in Cajamarca affirms that "sessions create a safe space where people feel supported, held, energised and relaxed at the same time, creating conditions for better community cohesion, and a happier society. When used with children it is noticed that they become much more confident and motivated to reach their full potential." She believes that this can change and help communities to heal and build a different future. 
Sessions have proved to be effective in creating a safe environment and acknowledging the group energy whatever this might be (tired, sad, etc.). Doing the practices in a circle confirms what Lederach (2010) and several authors propose, that the notion of healing and reconciliation involves cyclical or circular movements.

\section{d. Gaining cohesion, integration and building trust}

All groups participating in this experience enjoyed the ambiance created by Capacitar and Laban Dance practices: the gradual release of tension and tiredness, the gentleness of the process, the sense of peace, relaxation and freedom, the smiles, the groups working in creating their pieces or movement sequences. People felt comfortable in their bodies, not judged and free to either move along with the group or create their own pieces. It showed how dance and body movement create cohesion, integration and inclusion. It was also observed that those most traumatised have less mobility and less flexibility to create movement or to move along with others. However, it was seen that the practices helped those most restricted to liberating and improving their capacity to move and express themselves.

Providing SELF help tools for community leaders and community development practitioners.

Self-Care or "autocuidado" (in Spanish) is a theme that is being introduced in community development work in Colombia as symptoms of burn-out or vicarious trauma start to become apparent affecting teams and community based organisations. This is considered of high importance in the agendas of these groups as people tend to keep going, to overlook their tiredness, working longer hours and not finding time and effective ways to restore their energy. This is affecting peoples' health and family dynamics. Participants benefitted immensely from the practices. Stress rates at the beginning of the sessions were close to 10; high on a scale from 0 (lowest) to 10 (highest). However, at the end of the sessions, they showed a large reduction to 2 or 3 in some cases.

Capacitar and Laban Dance proved to be effective tools, easy to learn and to practice individually (Capacitar) and as a group in order to help to keep the physical and mental health of activists working in development and peace efforts, as well as advocacy initiatives in such stressful environments.

\section{Conclusions}

This paper reflected on how Capacitar and Laban Dance as two combined approaches of Body movement and Dance can support Social Transformation processes which are complex and require creativity to address the challenges presented to communities, especially those caught in the middle of violence. Dance and body movement offer communities important non-verbal tools to sustain social change, deal with conflict in a holistic manner in thelong-term.

Dance and movement practices as Capacitar and Laban Dance have proved to be effective in addressing trauma, PSTD symptoms at individual level and at group level reducing or eliminating physical symptoms of stress and PTSD and creating safer environments where groups can enjoy being together. 
By addressing trauma at physical and mental level, conditions for more participation and effective social processes can be created to allow community healing.

The Peace and Wellness project using Capacitar and Laban Dance, as an initial exploration, provides evidence on how these approaches can be useful to create conditions for resilient and healthier communities, where trauma is addressed and where a strong basis is built towards for more sustainable conflict solving processes.

Dance and Body movement approaches offer a path to improve people's capacity to integrate communicate and function better as individuals in body, mind and spirit and as a group. The STA project and Lederach's concepts of resilience provide a framework to keep up studying how groups can benefit from these practices on a large scale. More research is required to prove how these practices help groups to demonstrate this widely. 


\section{References}

Alexander, N. and LeBaron, M. Building Kinesthetic Intelligence (2013) In: The Choreography of Resolution.ABA, US

Ascencio, C.L. (2015) Black Girl Dangerous.

Availableat:http://www.blackgirldangerous.org/2015/09/caring-for-each-other-after- violence-4-thingswe-can-do-to-create-trauma-informed-communities-in-our-schools- organizations-and-activist-groups/] ( accessed 15 February 2016)

Clancy, M.A. \& Hamber, B.(2008) Trauma, Peacebuilding, and Development: An overview of key positions and critical questions.Paper presented at the Trauma, Development and Peacebuilding conference, New Delhi, India, September 2008. Available at:http://www.incore.ulst.ac.uk/pdfs/IDRCclancyhamber.pdf ( accessed 15 February 2016)

Davis, R. and D.M. Franks (2011) The costs of conflict with local communities in the extractive industry. 2011. First International Seminar on social Responsibility in mining.

Chile.Available at: http://shiftproject.org/sites/default/files/Davis\%20\&\%20Franks_Costs\%20of\%20Conflict_S

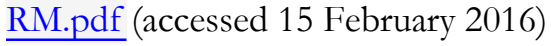

Doung, N (2013) Dance as Therapy TEDx Stanford. Available at: https see : Tal Shafir - How your body affects your happiness. [https://www.youtube.com/watch?v=ljm0ldxgkcE]

Driessen, Peter P.J. (2013) Societal transformations in the face of climate change. Netherlands:Copernicus Institute of Sustainable Development, Utrecht University. Available at: http://www.jpiclimate.eu/media/default.aspx/emma/org/10829915/Paper+Societal+transformations+in+ the + face + of + climate + change +-+ April $+2013+$ JPI + Climate.pdf( accessed 15 February2016) Duran, Mauricio (2004) Alternatives to War: Colombia Peace Processes. In: Accord- Colombia. Conciliation Resources, UK: Conciliation Resources. Available at: http://www.c- r.org/accord/Colombia (Accessed 15 February 2016)

Hope, A. \& Timmel, S. (2013) Partners Training for Transformation working for social justice through grassroots community education. Available at : http://www.trainingfortransformation.ie/index.php/what-wedo/courses/training-for- transformation ( accessed 15 February 2015)

Kirmayer, L.J., Lemelson, R. and Barad, M.(2007) Introduction: Inscribing Trauma in Culture, Brain, and Body. In:Understanding Trauma. Integrating Biological, Clinical, and Cultural Perspectives, Division of Social and Transcultural Psycbiatry, Cambridge University Press. Available at:

http://www.cambridge.org/us/catalogue/catalogue.asp?isbn=9780521854283\&ss=exc (accessed 15 February 2016). See also Levine, Peter (1997) Walking the Tiger, Healing Trauma. Berkeley CA :North Atlantic Books. . Chapters $4 \& 5$.

Laban Guild for Movement and Dance, UK. Available at: http://www.labanguild.org.uk/ (accessed on $15^{\text {th }}$ February 2016) 
Le Baron, M. and Cohen, C.( 2013) Breathing Life into the Ashes: Resilience, Arts and Social Transformation. In: PWIAS Inaugural Roundtable, Final Report. US: Brandeis University International Center for Ethics, Justice \& Public Life

Lederach.J.P.(2005) The Moral Imagination: The Art and Soul of Building Peace. Oxford, MA: Oxford University Press

Levine, P.(1997) Walking the Tiger, Healing Trauma. Berkeley CA: North Atlantic Books. Chapters 4\&5 Lindley, A.(2014)Crisis and Migration: Critical Perspectives. Routledge Studies in Development, Mobilities and Migration. London and New York: Routledge Pease, M. (2015) Post Traumatic Stress Disorder-Symptoms. Emedicinehealth. Available at:http://www.emedicinehealth.com/post-traumatic_stress_disorder_ptsd/page3_em.htm(accessed 15 February 2016) Conversation with Mark Cumming, former Programme Human Rights and Governance Officer based in Rwanda in the years after the genocide (November, 2010) Sonpar, S. (2008). Trauma, Development, and Peacebuilding Cross- Regional Challenges: South Asia. Paper presented at the Trauma, Development and Peacebuilding Conference.

New Delhi, India. September 2008. Available at: http://www.incore.ulst.ac.uk/pdfs/IDRCsonpar.pdf (accessed 16 February 2016)

Lederach, J.P and Lederach, .J. (2010) When Blood and Bones cry out: Journeys through the soundscape of healing and reconciliation. Australia :UQP

Rebmann, J. \& Cane, P. (2011) Capacitar: Healing Trauma, Empowering Wellness. Impact Research Report. USA: Capacitar International

Sullivan,L,(2014) www.developmenteducationreview.com/issue19-perspectives4 (accessed 16 February 2016)

Wessells, M.(2008) Trauma, Peacebuilding and Development: An Africa Region Perspective. Paper presented at the Trauma, Development and Peacebuilding Conference. New Delhi, India, September 2008: 2.Available at: http://www.incore.ulst.ac.uk/pdfs/IDRCwessels.pdf ( accessed 15 February 2016) 
Patricia (Patty) Abozaglo, Adjunct Faculty at Maynooth University- Edward Kennedy Institute, is a Peruvian Human Rights lawyer. She holds a MA in Development Studies (Honours) from Kimmage Manor Development Studies Centre (Ireland) with a thesis on the role of NGOs in Peacebuilding in Colombia. Living in Ireland for the past twenty years, she worked with Trócaire (Irish Development Agency) as Colombia programme manager, peacebuilding advisor globally and Regional Liaison Officer for East Africa. Patty is a fully qualified Capacitar International Tutor (Multicultural awareness and trauma healing Programme) and a Laban Guild (UK) Community Dance Leader (Grant recipient 2010, Arts council Co. Kildare). For the past ten years' years, she has run various workshops using these innovative approaches as tools for empowerment and wellbeing in development and peacebuilding work in Ireland, and various countries in Africa, Asia and Latin America. In Ireland, workshops hosted by the Kildare Arts Service and Public Libraries have helped members of her community to overcome stress created by the recession. In Africa, workshops have helped Trócaire Staff to cope with highly stressful conditions and highly conflictive environments in addition to heavy workload. Since 2013, Patty has been leading the project Capacitar and Laban Dance for Peace and Wellness in Latin America; supporting local NGOs and victims of violent conflict in Colombia and mining communities in Peru, using these methodologies to help restoring social fabric and trauma recovery where people have been affected by collective trauma or secondary (vicarious) trauma. On a part time basis, she also works as an independent consultant and facilitator supporting various Irish charities working in development overseas. 